\title{
Associação de urticária de contato e dermatite alérgica de contato à borracha"
}

\author{
Association of contact urticaria and allergic contact dermatitis to rubber
}

\author{
Ohalis Luanda Fernadez ${ }^{1}$ \\ Rosana Lazzarini ${ }^{3}$
}

\author{
Juliana Macedo Canosa ${ }^{2}$ \\ Ida Duarte ${ }^{4}$
}

\begin{abstract}
Resumo: Apresenta-se o caso de uma profissional da área da saúde que desenvolveu reação de hipersensibilidade dos tipos I e IV à borracha. O quadro clínico mostrava dermatite eczematosa no dorso das mãos. O teste de contato foi positivo para o grupo tiuram, assim como o teste aberto com fragmento de luva após exposição de 20 minutos. A dosagem de IgE sérica (Rast) mostrou-se relevante. As reações aos alérgenos da borracha são frequentes entre os profissionais da saúde, devido ao contato constante com esse material. Palavras-chave: Borracha; Dermatites alérgicas de contato; Dermatite ocupacional; Hipersensibilidade ao látex; Látex; Luvas cirúrgicas; Urticária

Abstract: We present a case of a healthcare professional that developed type I and IV hypersensitivity reactions to rubber. During the clinical examination the patient showed eczematous dermatitis of the hands. The patch test was positive for thiuram group and an open test with a piece of glove was positive after 20 minutes of exposure. Allergen-specific IgE test (RAST) was relevant. Reactions to rubber allergens are frequent among healthcare professionals due to constant contact with this material.

Keywords: Dermatitis, allergic contact; Dermatitis, occupational; Gloves, surgical; Latex; Latex hypersensitivity; Rubber; Urticaria
\end{abstract}

\section{INTRODUÇÃO}

A dermatite alérgica de contato (DAC) com borracha é causada pelo mecanismo de hipersensibilidade do tipo IV (Gell e Coombs), relacionado principalmente aos agentes vulcanizadores, como o tiuram e os carbamatos. Em frequência menor ocorre concomitantemente a reação do tipo I ao látex ou urticária de contato (UC). Esta última é comum em profissionais da área da saúde, devido ao contato constante com materiais contendo látex, como luvas e garrotes. Relata-se o caso de uma profissional da área da saúde que apresentou reação de hipersensibilidade do tipo I (UC) e tipo IV (DAC).

\section{RELATO DO CASO}

Paciente do sexo feminino, 40 anos, branca, bióloga, natural e procedente de São Paulo (SP). Há quatro anos, compareceu ao serviço de dermatologia com dermatite eczematosa das mãos, quando foi submetida a testes epicutâneos, que se mostraram negativos. Foi feito o diagnóstico de dermatite de contato por irritação primária nas mãos, sendo tratada com corticosteróides tópicos e emolientes, além da recomendação do uso de luvas com proteção de tecido.

Retornou ao ambulatório após quatro anos com queixa de prurido e eritema no dorso das mãos, presentes há duas semanas. Relatava que três meses antes apresentara dispnéia após uso de luvas de látex, necessitando de assistência em unidade de emergência, onde foi medicada para broncoespasmo.

\footnotetext{
Recebido em 14.12.2006.

Aprovado pelo Conselho Consultivo e aceito para publicação em 19.12.08.

* Trabalho realizado no Ambulatório de Dermatologia do Hospital da Santa Casa de Misericórdia de São Paulo - São Paulo (SP), Brasil. Conflito de interesse: Nenhum / Conflict of interest: None

Suporte financeiro: Nenhum / Financial funding: None

Dermatologista formada pela Faculdade de Medicina da Santa Casa de Misericórdia de São Paulo - São Paulo (SP), Brasil. Dermatologista formada pela Faculdade de Medicina da Santa Casa de Misericórdia de São Paulo - São Paulo (SP), Brasil.

Médica assistente do Setor de Alergia e Fototerapia da Clínica de Dermatologia da Santa Casa de Misericórdia de São Paulo - São Paulo (SP), Brasil.

Médica, primeira assistente e responsável pelo Setor de Alergia e Fototerapia da Clínica de Dermatologia da Santa Casa de Misericórdia de São Paulo São Paulo (SP), Brasil.

(C)2009 by Anais Brasileiros de Dermatologia
} 
A história clínica revelou, ainda, queixa de prurido vulvar após contato com preservativo e após exame ginecológico, além de edema dos lábios ao encher balões de festa.

No exame dermatológico notava-se a presença de dermatite eczematosa no dorso de ambas as mãos, sem comprometimento das regióes palmares.

Com a hipótese diagnóstica de dermatite alérgica de contato, associada à urticária de contato, a paciente foi submetida a novos testes de contato.

O teste de contato efetuado com o emprego da bateria padrão brasileira (FDA - Allergenic/RJ - Brasil), com leituras realizadas após 48 e 96 horas, mostrou positividade para o grupo tiuram (Figura 1). Apresentou também reação imediata à borracha no teste aberto realizado com fragmento da luva da paciente (Figura 2). A dosagem de IgE sérica especifica para látex (Rast Radioallergosorbent test) encontrava-se elevada (14KU/1), desde que valores acima de 3,5KU/1 são considerados relevantes para alergia ao látex.

Diante desses dados foi confirmado o diagnóstico de urticária de contato com o látex (associada a sintomas respiratórios) e de dermatite alérgica de contato com o grupo tiuram.

A troca das luvas e orientações quanto a evitar possíveis contatos com o látex foram suficientes para manter o controle da doença.

\section{DISCUSSÃO}

O látex natural é emulsão proveniente de uma árvore, a Hevea brasiliensis, popularmente conhecida como seringueira. Essa emulsão é composta por produto intracelular complexo (cis-1,4 poliisopreno) e uma série de proteínas, muitas delas caracterizadas como alérgenos (Hev b1 a Hev b11). O processo de fabricação da borracha inclui a adição de substâncias químicas, como os carbamatos e tiurans, capazes de conferir-lhe

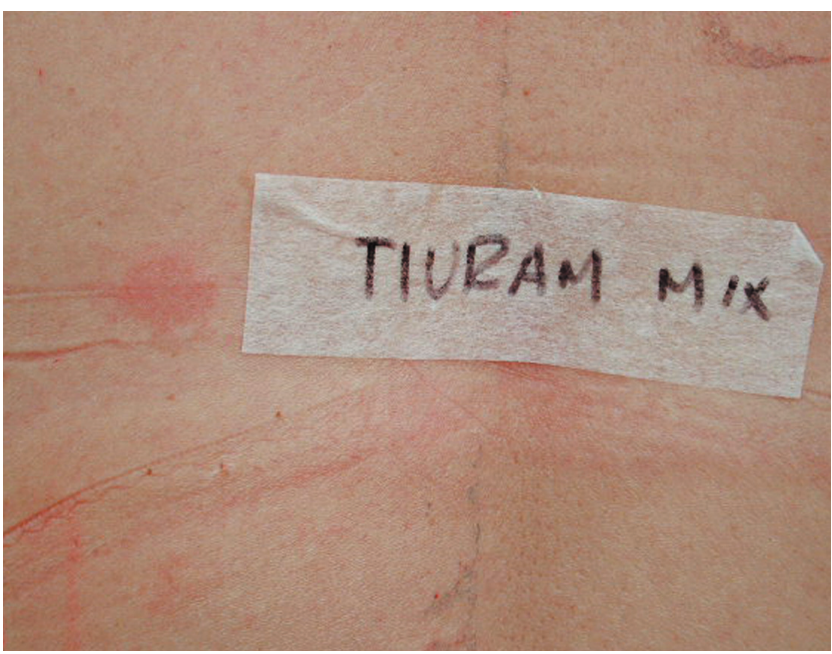

Figura 1: Teste de contato positivo ao Tiuram-mix características como elasticidade e longevidade.

A borracha na forma de luvas pode causar diferentes tipos de reações ao indivíduo que as utiliza, como a dermatite de contato por irritação primária, a dermatite alérgica de contato com aditivos químicos e a urticária de contato. Esta última, associada a sintomas respiratórios, é desencadeada pelo contato com as proteínas do látex natural, através de soluções de continuidade da pele, do sistema respiratório ou das mucosas.

A necessidade de proteção contra doenças infectocontagiosas, a partir dos anos 80, tornou o uso das luvas de látex obrigatório e constante entre os profissionais da saúde, o que provocou outro risco ocupacional, a urticária de contato.

A frequência de reações ao látex nos países desenvolvidos elevou-se, acarretando uma série de recomendações e medidas preventivas. Algumas delas, como a criação de comitês de estudo sobre o látex, centros cirúrgicos especiais, artefatos de materiais alternativos, resultaram em posterior queda no número de reações graves. ${ }^{1,2,3}$ A prevalência de sensibilização ao látex na população geral é de $1 \%$, mas entre trabalhadores da área da saúde varia de três a 14\%.1 A maior fonte de reações ao látex relaciona-se ao contato com luvas, sendo a frequência da exposição mais importante do que sua duração para se induzir a sensibilização. ${ }^{4,5,6}$

O talco das luvas atua como carreador das proteínas do látex, levando-as ao sistema respiratório, e, portanto, pessoas ocupacionalmente expostas a luvas de borracha com talco têm risco aumentado de desenvolver rinoconjuntivite e asma. ${ }^{6}$ As proteínas do látex são absorvidas lentamente após exposição aérea, e os sintomas se desenvolvem aproximadamente 30 minutos após o contato. As luvas com pó liberam partículas com proteínas do látex capazes de desencadear sintomas respiratórios por meio de mecanismos mediados pela IgE. ${ }^{7}$

Apesar da relativa frequência desses casos entre

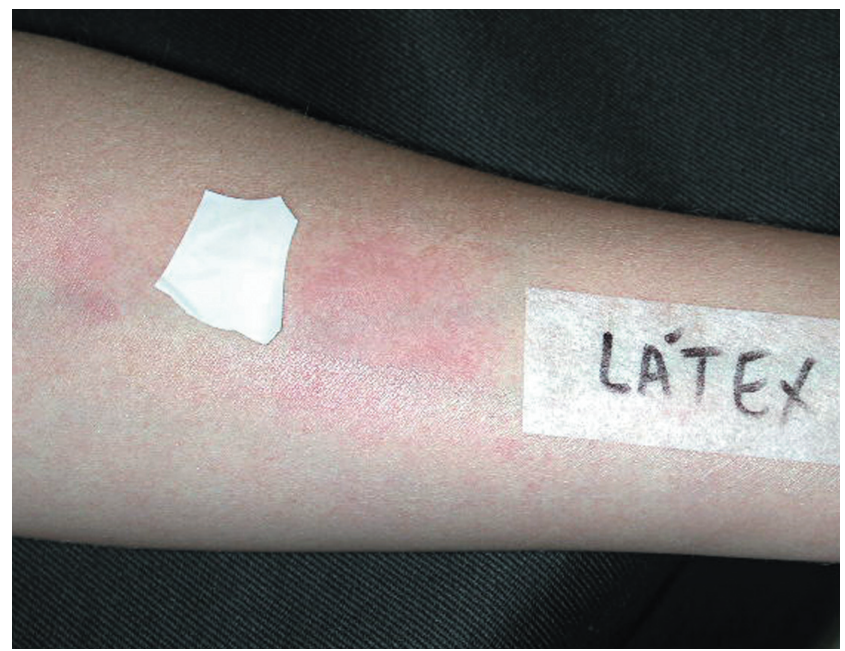

Figura 2: Teste aberto positivo para fragmento da luva 
os profissionais da saúde, esse é o primeiro observado pelos autores, tendo sido comprovada a presença das duas entidades no mesmo indivíduo.

São reconhecidos alguns fatores de risco para o desenvolvimento de alergia ao látex, como, por exemplo, ser profissional da área da saúde e da indústria da borracha; ter sido submetido a múltiplas cirurgias para correção de anomalias congênitas; exposição frequente das mucosas (procedimentos odontológicos, uso de coletores de urina ou sondas); presença de dermatites de contato alérgica e irritante, além da atopia. ${ }^{5}$

Alguns alimentos podem desencadear reações cruzadas com o látex, como, por exemplo, banana, kiwi, mamão, pêssego e amendoim; isso ocorre pela presença de proteínas semelhantes àquelas do látex. ${ }^{8}$

No caso descrito, a paciente apresentou como fatores de risco a atividade profissional, a presença de dermatite de contato por irritação primária e, posteriormente, dermatite alérgica de contato com os aditivos da borracha. Esta última caracteriza-se pela presença de dermatite eczematosa no dorso das mãos, dedos, punhos e antebraços. ${ }^{9}$ O grupo tiuram é o principal sensibilizante presente nas luvas de borracha, tanto de uso hospitalar quanto doméstico e industrial. ${ }^{10,11,12}$

A associação de dermatite alérgica de contato e

\section{REFERÊNCIAS}

1. Grippa M, Belleri L, Mistrello G, Carsana T, Neri G, Alessio L, et al. Prevention of latex allergy among health care workers: evaluation of the extractable latex protein content in different types of medical gloves. Am J Ind Med. 2003;44:24-31.

2. Belsito DV. Occupational contact dermatitis: etiology, prevalence and resultant impairment/disability. J Am Acad Dermatol. 2005;53:303-13.

3. Geier J, Lessmann H, Uter W, Schnuch A; Information Network of Department of Dermatology (IVDK). Occupational rubber glove allergy: results of the information Network of Departments of Dermatology (IVDK), 1995-2001. Contact Dermatitis. 2003;48:39-44.

4. Patriarca G, Nucera E, Buonomo A, Roncallo C, De Pasquale T, Pollastrini E, et al. New insights on latex allergy diagnosis and treatment. J Investig Allergol Clin Immunol. 2002;12:169-76.

5. Gottlober P, Gall H, Peter RU. Allergic contact dermatitis from natural latex. Am $\mathrm{J}$ Contact Dermatitis. 2001;12:135-8.

6. Hepner DL, Castells MC. Latex allergy: an update 2003. Anesth Analg. 2003;96:1219-29.

7. Warshaw EM. Latex allergy: continuing medical education. J Am Acad Dermatol. 1998;39:1-24.

8. Zucker-Pinchoff B, Stadmauer GJ. Latex allergy. Mt Sinai J Med. 2002;69:88-95. urticária de contato, no mesmo indivíduo, é ocorrência de difícil diagnóstico e pouco frequente, mas presente em alguns relatos da literatura, principalmente os que focalizam profissionais da saúde. Num desses estudos, observou-se que 33 (61\%) dos 55 trabalhadores de um hospital tinham dermatite de contato por irritante primário (DCIP), ${ }^{17}$ (31\%) dermatite alérgica de contato (DAC) e 14 (27\%) urticária de contato (UC). Nesse grupo, seis trabalhadores (11\%) apresentavam concomitantemente DAC relativa à borracha e UC pelo látex. ${ }^{10}$

Algumas medidas adotadas pelos fabricantes contribuíram para diminuição do número de ambas as reações. Quanto à urticária de contato, a confecção de luvas com menor teor de proteínas e sem talco, utilizando outros materiais, como vinil, nitrilo, cloropene ou tactylon, contribuiu para a diminuição das taxas de sensibilização. ${ }^{1}$ Recentemente, algumas observações sobre sensibilização ao tiuram mostram sinais de queda na Dinamarca, onde recomendações de alguns comitês europeus foram acatadas pelos fabricantes de luvas, tendo esse agente sido substituído por um carbamato (dibutilditiocarbamato) de menor potencial sensibilizante. ${ }^{13}$

O relato deste caso mostra a dificuldade diagnóstica da associação entre as duas entidades no Brasil.

9. Edelstam G, Arvanius L, Karlsson G. Glove powder in the hospital environment - consequences for healthcare workers. Int Arch Occup Environ Health. 2002;75:267-71.

10. Arnau-Gimenenez AM. Health Personnel. In: Frosch PJ, Menné T, Lepoittvin JP, editors. Berlin: Springer- Verlag; 2006.p.735-49.

11. Rietschel RL, Fowler JF. Allergy to rubber. In: Rietschel RL, Fowler JF, editors. Fisher's contact dermatitis. Philadelphia: Lippincott Williams and Wilkins; 2001.p.533-60.

12. von Hintzenstern J, Hesse A, Koch HU, Peters KP, Hornstein OP. Frequency, spectrum and occupational relevance of type IV allergies to rubber chemicals. Contact Dermatitis. 1991;24:244-5.

13. Knudsen B, Lerbaek A, Johansen JD, Menne T. Reduction in the frequency of sensitization to thiurans. Contact Dermatitis. 2006;54:170-1.
ENDEREÇO PARA CORRESPONDÊNCIA / MAILING ADDRESS:
Ohalis Luanda Fernadez
Rua Dr Chibata Miyakoshi, 350 ap 252, Panamby
05705170 - São Paulo SP
Tel./fax: (11) 91906375
e-mail:ohalis@botmail.com

Como citar este artigo/How to cite this article: Fernandez O, Canosa JM, Lazzarini R, Duarte I. Associação de urticária de contato e dermatite alérgica de contato com borracha. An Bras Dermatol. 2009;84(2):177-9. 